right side of each eye is blind, which makes me anxious when I drive, especially when it's dark or I'm tired. All of this seems so reasonable, then, that it seems to me very much like what we all see in dreams, or ghosts seen in the closet by easily frightened children. There are, however, several additional points to mention.

Firstly, obviously some people see more unusual visions, even when theirs are also results from a stroke. A good, kind, and religious friend of mine was depressed (as all stroke patients feel in the first year). She also couldn't see on the right, like me, but (as she mentioned in a letter), several times she saw angels, dressed in white ... but only on the right.

Another point: $m y$ visions are more dramatic than the ghost in the closet type, or even the pictures in my dreams, which are rather vague, and never coloured. My ghost cars are not as clear as real cars right in front of my eyes, but they are not shadows, either. They have colour-one was a bright green-and are distinctly recent standard American automobiles; so far, none has been foreign, or red, or expensive. Not being a vehicle lover I cannot tell the reader any of the cars' makes; when I tried instantly to see a car in my mind's eye, however, my first reaction was a page in the automobile section in the Sunday Boston Globe. My next picture (very fleeting) was the used car lot in town, and I believe that one of its cars was a newly painted green. At any rate, I am never pleased by a false picture: it means I shouldn't be driving, but it also doesn't frighten, or suggest that I should found a new vehicle cult.

One final point: the blind side of my vision is neither black nor blank (that is, white). This is one of the major problems; since there is light and colour on both sides of my vision I often forget-even eight years after the stroke-that there may be real things which I am not seeing in an area where I think I can see. Very often I bump and break things on the right; sometimes I get confused when reading because I don't notice that there is another word at the end of the line. These things seem to happen from another fake vision of my brain; rather than seeing a blank area my eyes seem to "paint" a reasonable but fake picture. In the beginning I often saw people with only one eye (always their right, seen on my left, of course); now all people have two eyes.

But it is always possible that the second eye I see on someone's face is just as false (that is, not really seen) as someone else's angels. Now, I'm not a disciple of Plato, but when he says that we shouldn't necessarily believe our senses he certaintly has a point.

Wheaton College, Norton, Mass 02766, USA

DOROTHEA WENDER, PHiD, professor of classics

\title{
"Blow the Wind Southerly": extracts from a novel
}

\author{
THOMAS SHERWOOD
}

\section{London}

More rolls of lavatory paper and bars of soap. Peculiar packing for this trip-the usual two weeks' lecture tour to the States needed a few shirts, vests, pants, socks. He had learnt not to fuss around with too much: American universities didn't expect dinner jackets when they dined him out. And the hotels could always wash his things in a day. This time he is taking a much bigger suitcase. The bottom layer is already thick with packets of brown rice, flour and candles. Then the bars of soap. His clothes on top of this are only three or four inches deep, followed by the lavatory rolls. They started off as cylinders but squash up into flat, dumpy ovals when he forces the case shut, so there is room for more. The 15 paperback textbooks will go into the small case he can take with him on the 'plane. Together with his lecture slides and washing things. He leaves both cases open overnight, ready for a final check in the early morning before he leaves for the airport. He climbs into bed, tries to read Tom Paine's Rights of Man, fails, and drops asleep.

The airport is best reached by train. At 7 am London is still rubbing its eyes, and the large railway station is bright with empty space and sun. He puts his cases down at the gates to platform 13, and waits. Half exhilarated by the journey to come, the morning, the taste of the moment. The other half is foreboding. It is cold for early May. Who will come?

No one for a while. The occasional early traveller sees a man with one large and one small suitcase, standing with folded arms outside platform 13 . He seems to be somewhere around 40, unremarkably dressed except for wearing a hat. An early commuter train arrives on platform 12, and a few people walk off it, past him. The station clock moves to $710 \mathrm{am}$. At last someone approaches, a young man in jeans-looks like a student. He is clearly not sure of the man with folded arms, but after a few words both smile, and the young man pulls out three envelopes from his denim jacket. They are put into a large pocket of the small suitcase. As the two are about to say goodbye, a girl in her teens arrives, very pretty, hugs the young man her brother, and gives Philip more letters to pocket. Both leave at once, but Philip stays with his suitcases. In the next 20 minutes, as the cold spring morning tries to warm up, more people come one by one. They clearly do not know Philip, have arranged to meet the man at platform 13, and give him various envelopes, some quite thick. After a few words they hurry on. By 730 am the hurry is general, growing into the early London rush-hour. Trains arrive more frequently, spit out more people. Through the barrier, and down the stairs to the underground in that characteristic, look-neither-left-nor-right progress: anonymous Londoners sleepwalking their way to work. Philip wonders whether he too can go off now, in the opposite direction. One more messenger accosts him, black, the briefest of any of them, pressing a single letter into his hands. There is barely room in any suitcase pocket now. Philip picks up his bulging luggage, squeezes past the barrier and onto a train just leaving for the airport.

\section{Kisuti}

The session was cut short at noon by a messenger: the bishop's wife was waiting, when would Dr Edgehill come to see her in the officer-of-the-day's room?

The bishop's wife had fewer gold teeth than her husband but overall was bigger still. She sat surrounded by three adult daughters, and all were in quite expensive looking European dresses, with no holes at all. Bracelets clinked when they talked with their hands. The daughters saw themselves as so many interpreters. Philip quickly sent out two of them to lessen the chaos. They left reluctantly and stood in the doorway of the open room. Now and then a passerby would stop to look and listen with them, until shooed off by Philip. The officer of the day had wisely absconded long ago.

"Please ask your mother what she complains of."

There was lengthy and loud chatter between the two women. 
When it stopped Philip waited expectantly, but after a pause it all started up again. He interrupted:

"Well, what does she say?"

"She has a big headache."

"What, is that all she said?"

"No, doctor, it is a very big, very bad headache."

"All right. Just translate one sentence at a time for me please. How long has she had the headache?"

Another long twosome was under way, so Philip interrupted again: "Well?"

"It is a terrible headache."

"No, please ask her how long she has had it."

Yakety yak.

"She also has this very bad pain in the kidneys."

It was exasperating. Philip fastened on to the new symptom. "Where is that pain now?"

Shim shum.

"She does not have the kidney pain this morning."

"I should like to know where she herself says she feels the painplease ask her to describe it."

The chatter a little irritated now.

"But she already tell you. It is in her kidneys."

"Where is that in her? Can she show me?" belly:

The daughter reached across and dug Dr Edgehill smartly in mid-

\section{"In the kidneys!"}

He wasted over half an hour on the bishop's wife. She was fit as a fiddle, and very displeased when he told her so through her daughter. Then the bishop came back.

He was flanked by the two huge bodyguards and introduced them - they were his sons. This one had a bad hip, and this daughter outside had trouble with her periods. Would Dr Edgehill be so kind as to see them next? Philip excused himself, he was too busy on the infectious diseases unit for further consultations, and not an expert in such problems anyway. Well, the bishop said, there was just one other small matter. The second daughter, this one, wanted a new pair of glasses, and could Dr Edgehill, back in London . . . Philip fled.

\section{Brulu}

Philip remembered this second day in Brulu as his personal worst. They arrived back at the hospital in good time for his seminar, and he was taken to the fifth floor of the large building, to the department of medicine's two rooms. One was an empty office Dr Glossop was trying to start up for the medical students, and the other the seminar room. The empty office did contain a desk and Anthony, a thin young clerk. Philip had been led up various staircases, and then right through one of the wards on the fifth floor. Building the hospital had been another act of faith those many years ago, a six storey concrete structure overlooking the city, the tallest for hundreds of miles. Its roofs were manned by vultures who enjoyed the look-out and the scavenging. Money had already run short during construction; a whole wing of the place had never been finished, and now stood rotting. The architects too had become demented with grandeur. For the sake of striking external looks, they had done without communication corridors between blocks. The wards themselves had to serve as passage ways, and everyone and everything trundled straight through, past patients in beds or on the floor. Philip had to take care not to tread on limbs thrown out across his path on the way to his seminar.

A ward five floors up on a hill over Brulu had other drawbacks, he now found out. Lunch at the restaurant had been a mistake. There were uncomfortable rumblings inside him in the car on the return journey to the hospital. By the time he reached the department of medicine he knew he was in trouble. There were 10 minutes till the start of the seminar. He asked Anthony to show him a lavatory, hoping that one prophylactic visit might deal with the mounting protest within him. Anthony looked sheepish, took Dr Edgehill a turn down a passage, and pointed to a corner "just round there." Then he left. Philip found something he had not seen before. The lavatory bowls were set in a row of cubicles, all doors disappearing long ago. Each bowl was aswim with the faeces passed by its multiple occupants for the last 48 hours. The water pressure was habitually poor, and could not have reached to this level for days. To complete the picture of the spattered, laden bowls, the floor beside them was strewn with many crumpled bits of paper. There was no supply of lavatory rolls: these were the stained wads already used, laid out to dry so that the next man or woman might have something.

"A caring society" Philip thought, trying to distance himself from the disaster before his eyes and that beckoning within him. His need was pressing, but this was too awful.

They picked up Isaiah half an hour later. He jumped up from where he had been sitting by the roadside. It was the middle of nowhere just as before. Isaiah laughed as he climbed in beside $\mathrm{Mr}$ Inivoru at the front. He began a fast and loud conversation with Paul Kimjinge the moment they were under way again. The words tumbled out-a debriefing session, Philip imagined. Inivoru had talked to Dr Kimjinge long and earnestly after leaving Agimbo, a sedate report by the sound of it. This was a rollicking account in contrast; even sober $\mathrm{Mr}$ Inivoru slapped his thigh in delight at something shouted by Isaiah. Paul Kimjinge was laughing too, and went on to ask Isaiah a number of questions. He did not translate any of it for Philip, but in the end raised his thumb at him in the universal gesture of "it's OK." They fell silent as they peered ahead to the next meeting point, for picking up Anthony.

They arrived at the ravine a little early, some minutes before three o'clock. The road was empty. They drew in to the side and waited. The afternoon was warmer than the morning, and flies and heat buzzed inside the stationary Landrover. They were returning into the tropical rain forest, the mountains behind them.

At five minutes past three a woman carrying a baby on her back appeared in the clearing. She looked round, waddled up to the Landrover and spoke with Inivoru through the window. He turned round to Paul Kimjinge who was already opening his door and climbing out. Paul said "Trouble, Philip. Will you stay here with Inivoru please. Do not leave the Landrover. If anyone comes and asks for a lift, refuse. If you see soldiers coming, drive off at once before they can get into firing position. Inivoru knows the next rendezvous point. Should anyone question you, explain who you are and that you have just visited Agimbo Hospital. Alone-do not mention us. Come on Isaiah."

The two men ran into the forest ahead of the woman. She followed calling after them. Philip asked Inivoru "What's the matter?"

Inivoru, careful as ever, shrugged his shoulders. They waited.

A quarter of an hour later a party of black men naked to the waist came into the clearing, led by Paul. They carried a rough litter, made of a criss-cross of poles, and on it lay Anthony, bloody and unrecognisable. Isaiah ran up to the car. The Landrover was suddenly all intense and well organised activity, commanded by $\mathrm{Dr}$ Kimjinge. He sent two men as look-outs 100 yards up and down the road. He had the wire fencing manhandled out through the rear in a moment, and set the remaining men to bending it double. It was then reinserted, making a high platform in the back, with room by its side. The unresponsive shape that was Anthony was carefully put down on it. Isaiah and Paul jumped in beside him. Philip had stayed on the middle bench throughout these frantic minutes, watching helplessly. Paul Kimjinge shouted to the men, clenched his fist in a salute, the rear door was slammed shut, and Inivoru roared off. Philip saw the party scuttle into the forest as the men were lost from sight round a bend of the road.

Anthony rocked on the wire fence, his head just behind Philip. The hair was caked with mud and blood, the face a smeared red football, all features blotted out. His left eye, closed by grossly swollen lids, protruded unnaturally, making an obscene double with the child they had seen earlier on Dr Kampen's ward. Blood trickled from the sides of the mouth and also, ominously, from the left ear: a likely fracture of the skull base. Philip registered all this as 
he would when called to the victim of a traffic accident at home. Kneeling up on the middle bench of the lurching Landrover and bending over Anthony's head, he began to examine the face, eyes and neck. Paul Kimjinge in the back similarly undid Anthony's clothing, helped by Isaiah. He tested limbs, chest and abdomen. There was a good deal of bruising on the body, the clothes were in shreds, but everything above the neck had come off much the worst. Philip prised the eyelids apart gently and found the right eye intact. In the bloody crushed mess on the left he was sickened to see a small delicate fold of dark green directly under his examining finger: the eye had been stabbed, and that was a curtain of iris prolapsing through the wound. The clear stuff oozing there was fluid from the eyeball. Anthony was unconscious, taking slow, deep breaths.

The two doctors compared notes. Paul said "He's been badly knocked about but he's basically OK from the neck downwards. May have some rib fractures. How about your end?"

"Basal skull fracture, deeply unconscious, could be suffering further brain damage from bleeding inside the head right now. His left eyeball is cut, he probably won't see again with it. If he survives."

They reached the town on the main highway and turned. Inivoru asked "Do we stop?" and Paul said "No, straight on." The road surface became broken, and Anthony's frail body bounced up and down as the car weaved around potholes. Paul Kimjinge spoke to the others.

"Let's have our story straight. We've been to Agimbo Hospital, where they had this bad accident in. We don't know how it happened, but offered to take him back with us to Brulu because he needs skilled help, surgery. That's all we know."
The guards at the checkpoint were bored. They saw the human mess in the back, exchanged a few words and waved them through. The Landrover rattled on, the floor beneath Anthony's head stained by dripping blood.

"What happened?" Philip asked on the last leg to Brulu, when they had done all they could for the wounded boy. Paul Kimjinge shook his head in rage and sorrow:

"Don't ask. Anthony is one of my link men with the resistance in the mountains. The large village he was visiting has just been cleaned up by the People's Revolutionary Force. Someone must have told them he was coming. The People's Revolutionary Force set on him, stuck a knife in his eye for good measure, and left him to the villagers as an example. Loyal men brought him out later, and you've seen the rest. Do you think he'll live?"

Philip did not know. They had no difficulty with the roadblock into Brulu either, and drove straight to the hospital. Anthony remained unconscious for two days. Then he recovered, blind in one eye.

Blow the Wind Southerly by Professor Thomas Sherwood, from which these extracts are taken, may be obtained free of charge from Southerly, 28 Sopwell Lane, St Albans, Herts ALl 1RR. Donations are invited, however, to Intermediate Technology, a charity concerned with self help for the Third World.

\section{Cambridge CB5 8SU}

THOMAS SHERWOOD, FRCP, FRCR, dean, University of Cambridge School of Clinical Medicine

Correspondence to: 36 Church Street, Fen Ditton, Cambridge CB5 8 SU.

\section{Death by degrees}

\section{ANDREW ROBINSON}

\section{Introduction}

There is sufficient good advice available to graduates in medicine for young doctors to be very well informed about many matters affecting their choice of career..$^{1}$ Assuming, however, that our young doctor is progressing in his choice of career to the satisfaction of himself and others, it is much harder for him to obtain information pertaining to his own longevity. It is, of course, possible to reduce personal risk factors, particularly in relation to smoking, ${ }^{2}$ and, though alcoholic doctors have a gloomy prognosis, ${ }^{3}$ alcohol in moderation may not only enhance enjoyment of life but also marginally prolong life. ${ }^{4}$

This study was designed to give some further career guidance to any young doctor wishing for a longer life.

\section{Method}

The General Medical Council (GMC) register of the names of all medical practitioners erased after confirmation of death was examined for 1986 . The sex, year of initial graduation, year of graduation for a higher degree (where applicable), and qualifications were noted, but, as the precise age at death was not known and there was no information on specialty, obituaries from the British Medical foumal (BMF) for 1986 were used to supplement the information from the register.

I assumed that initial graduation occurred at the age of 23 (the midpoint for the quinquennium 21-25 years), and the frequency distribution of age at death was tabulated on quinquennial midpoints up to the age of 103 . Thus age at death for GMC erasures was calculated as the difference between the year of death and year of initial graduation with the addition of 23 years.

In calculating the standard error of the difference between population or sample means log (105-age) was used to correct for the skewed distribution of deaths. As the populations from the GMC data were large a standard normal distribution was assumed when comparing means. The smaller $B M \mathcal{F}$ sample means were compared with $t$ tests.

To make a substantial correction for bias in survival advantage-that is, the advantage conferred by surviving long enough to obtain a higher degree- deaths before the quinquennium $36-40$ years were excluded. The period up to the third quartile between initial graduation and obtaining an MD was 9.6 years (median $5 \cdot 1$ years).

\section{Results}

The GMC register recorded 1056 deaths, of which 883 were men. Women medical practitioners had a significantly higher mean age at death than men-77 $v 71$ (multiples of the standard error of the difference (SED) in the difference between $\log$ means $=5 \cdot 88$; see table for $\log$ means, $95 \%$ confidence intervals, and SD when these are not quoted in the text). The mean age at death for those who had a doctorate (MD) was significantly higher than the mean age at death for those who had a diploma of membership or fellowship of the royal colleges (multiples of SED in the difference between log means = 6.87) or for those who had a bachelor's degree or licentiate qualification (multiples of SED in the difference between $\log$ means $=8 \cdot 6$ ). Of those who had an MD, $12.8 \%$ were women compared with $16.9 \%$ of the remainder.

The $B M \mathcal{F}$ published 446 obituaries, 395 of which were for men. The mean age at death of each gender sample did not differ from the appropriate GMC gender population mean (for men multiples of SED in the difference 